\title{
Germaine de Staël und die Zweiteilung Europas
}

War Gertrudis Gómez de Avellaneda die große romantische Vermittlerin zwischen Europa und Amerika, Spanien und Kuba, europäischer Romantik und außereuropäischem Ambiente, so waren Alexis de Tocqueville und Flora Tristan unsere Zeugen für eine Zweiteilung Amerikas in ein Land der Zukunft und dem der Vergangenheit überantworteten ,Rest', zwischen einer materialistischen Lebensauffassung und einer an den spirituellen Wurzeln hängenden Latinität. Durch die nun folgende Beschäftigung mit Germaine de Staël, zumeist als Madame de Staël in die Literaturgeschichtsschreibung eingegangen, kehren wir nicht nur in den Zeitraum zurück, von dem wir von Frankreich aus nach Amerika aufgebrochen waren, sondern beschäftigen uns auch mit einer weiblichen Figur, die wie keine andere jener Zeit ebenfalls eine interkulturelle und transareale Vermittlerfunktion für Europa übernahm.

Germaine de Staël war die in Paris geborene Tochter des Schweizer Bankiers Necker, der zugleich Finanzminister der letzten Regierung des Ancien Régime und der ersten Revolutionsregierung war. Mit schwedischem Pass aus Frankreich exiliert, hielt sie in Coppet am Genfer See Hof, bereiste Italien, Deutschland, später Russland, Schweden und England. Sie vermittelte zwischen Frankreich und Deutschland sowie vielleicht mehr noch zwischen französischer Aufklärung und deutscher Romantik. ${ }^{1}$ Sie kann in diesem Zusammenhang nicht nur als zentrale Vermittlungsfigur für die deutsche Romantik nach Frankreich und vielleicht wirkungsvollste Propagandistin eines ganz bestimmten Deutschlandbildes gelten, sondern wurde durch ihre Schriften gerade auch für die ,neulateinischen' Literaturen beider Welten zu einer ganz entscheidenden Quelle der Auseinandersetzung mit Deutschland. Mit anderen Worten: Ihre Wirkung sowohl im französischsprachigen als auch im spanisch- und italienischsprachigen Raum kann schlechterdings nicht überschätzt werden, zumal sie auch in umgekehrter Richtung nach Deutschland vermittelte. Denn wer unter den Zeitgenossen etwas über die (deutschen) Ursprünge der Romantik erfahren wollte, schlug zunächst bei Madame de Staël nach.

Beschäftigen wir uns zunächst mit einigen für uns wichtigen Biographemen der Germaine de Staël, der großen Gegenspielerin des „Empereur Napoléon“! Anne-Louise-Germaine Necker, spätere Baronesse de Staël-Holstein, wurde am 22. April 1766 als Tochter des Genfer Bankiers und späteren französischen Finanzministers in der Hauptstadt Frankreichs geboren und starb am französischen

1 Vgl. hierzu Wehinger, Brunhilde (Hg.): Germaine de Staël. Eine europäische Intellektuelle zwischen Aufklärung und Romantik. Berlin: edition tranvía 2020.

2 Open Access. (c) 2021 Ottmar Ette, publiziert von De Gruyter. (c))BY-NC-ND Dieses Werk ist lizensiert unter einer Creative Commons Namensnennung - Nicht-kommerziell - Keine Bearbeitung 4.0 International Lizenz. https://doi.org/10.1515/9783110703443-018 


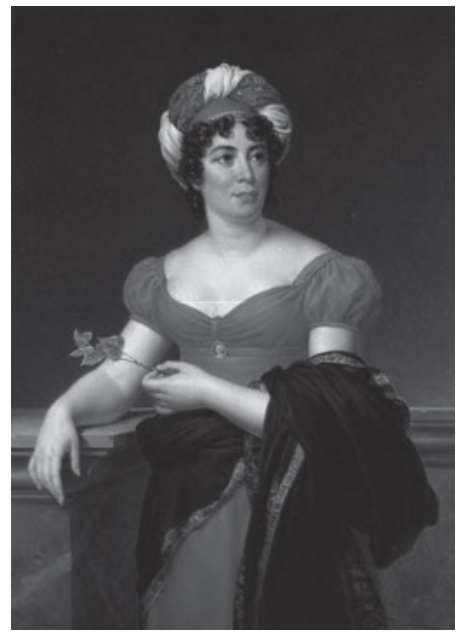

Abb. 43: Germaine de Staël

(Paris, 1766 - ebenda, 1817).

Nationalfeiertag, dem 14. Juli 1817, achtundzwanzig Jahre nach der Französischen Revolution in ihrem geliebten Paris. Im literarischen Salon ihrer Mutter lernte sie bereits als Kind die bedeutenden Vertreter der zeitgenössischen französischen Literatur kennen. Schon im Alter von zehn Jahren reiste sie erstmals für längere Zeit nach England und verfasste mit zwölf Jahren eine erste Komödie. Früh wurde sie als die einzige Tochter eines Genfer Bürgers aus reichem Hause literarisch sozialisiert und lernte das Who's Who der literarischen Zirkel kennen - eine Erfahrung, die sie für ihre späteren Aktivitäten als „Salonière“ nutzte. Bereits mit fünfzehn Jahren las sie erstmals Montesquieus De l'esprit des lois, eine Lektüre, die für ihr Denken bestimmend wurde. Wie ihre Mutter führte sie bald ihren eigenen literarischen Salon, der im Zeichen der historischen Veränderungen eine zunehmend politische Ausrichtung erhielt.

1786 ehelichte sie nach einem fehlgeschlagenen Heiratsprojekt mit Pitt dem Jüngeren den siebzehn Jahre älteren schwedischen Diplomaten Freiherr von Staël-Holstein, der 1802 starb, wenige Jahre nachdem man sich endgültig getrennt hatte. Germaine hielt sich nicht an eheliche Pflichten, sondern erfreute sich wie in ihrem gesamten Leben zahlreicher Liebhaber, denen sie als eigenständige und vitale Frau begegnete. Während der Französischen Revolution, die sie enthusiastisch begrüßte, stand sie mit ihrem Vater und ihrem damaligen Liebhaber, dem Grafen de Narbonne, auf Seiten der großbürgerlichen liberalen Girondisten. Während des Jakobinerterrors flüchtete sie sich in die Schweiz, auf ihr Schlösschen Coppet, und fügte einen Englandaufenthalt hinzu.

Schon zu Revolutionszeiten war sie durch ihre ausgezeichneten Verbindungen der Macht nah und zugleich im Zentrum des literarischen Lebens gewesen. Und auch später gelang es ihr eindrucksvoll, in Coppet einen Kreis berühmter 
Persönlichkeiten vom Schlage eines Chateaubriand oder Lord Byron, aber auch den als Hauslehrer ihrer Kinder engagierten August Wilhelm Schlegel um sich zu scharen, bisweilen Flüchtlinge und Exilierte aufzunehmen und so manche Liebschaft einzufädeln. Von 1795 an lebte sie wieder mit zahlreichen erzwungenen und privaten Unterbrechungen in Paris, wohin sie mit ihrem damaligen Liebhaber, dem Schriftsteller Benjamin Constant, zurückgekehrt war, bis sie 1803 wegen konspirativen Widerstands gegen Napoleon ins Exil gehen musste. Mit ersterem verband sie eine langjährige und enge, wenn auch anstrengende Liebesbeziehung, mit letzterem, den sie bereits vor seinem Aufstieg kennengelernt hatte, hingegen eine langjährige Beziehung gegenseitiger Abneigung. Dass sie während all dieser Jahre vier Kinder auf die Welt brachte, erscheint angesichts ihrer vielfältigen Aktivitäten im politischen und gesellschaftlichen, aber auch im literarischen Ambiente geradezu als ein biographisches Detail.

Germaine de Staël nutzte ihre Verbannung zu längeren Reisen nach Deutschland - von November 1803 bis April 1804 - sowie 1805 nach Italien, deren Eindrücke sie in De l'Allemagne und in Corinne ou l'Italie literarisch höchst einflussreich verarbeitete. Im Übrigen zog sie sich auf das Familienanwesen in Coppet am Genfer See zurück, wo sie einen permanenten literarischen Zirkel unterhielt, von dem sie sich auch bei gelegentlichen Frankreichaufenthalten begleiten ließ und der bald europäische Dimensionen entfaltete. Dort wie auf ihren Reisen gelang es ihr scheinbar mühelos, die literarisch einflussreichsten Gestalten ihrer Zeit um sich zu versammeln. Und auch sonst war sie auf Abenteuer aus: 1807 versuchte sie sich gemeinsam mit Madame Récamier vergeblich an einer Besteigung des MontBlanc. Auf ihrer Italienreise hatte sie in Neapel zwei Jahre zuvor auch Alexander von Humboldt getroffen, der bei einem Ausbruch des Vesuv sofort zu dem in voller eruptiver Aktivität befindlichen Vulkan eilte, um seine Untersuchungen anstellen zu können, dabei aber keine Frauen mitnehmen wollte. Der gerade von seiner mehrjährigen Reise in die amerikanischen Tropen zurückgekehrte Jüngere der beiden Humboldt-Brüder, der an Frauen kein Interesse zeigte, machte gleichwohl einen bleibenden Eindruck auf die noch junge Frau. Es mag vielleicht auch die gemeinsame Abneigung gegenüber Napoleon gewesen sein, welche die beiden miteinander sympathisieren ließ.

Die Bespitzelungen und Verfolgungen durch den napoleonischen Staat verschärften sich allmählich: Der Kaiser der Franzosen verfolgte Germaine de Staël mit außergewöhnlicher Beharrlichkeit und Härte. 1810 wurde De l'Allemagne in Frankreich verboten, seit 1811 wurde der Zugang nach Schloss Coppet scharf überwacht und für bestimmte Besucher gesperrt. Daher floh sie im Mai 1812 und reiste über Wien, Mähren und Galizien nach Russland, das sie in süd-nördlicher Richtung von Kiew über Moskau bis St. Petersburg durchquerte, um dann Herbst und Winter 1812/1813 in Stockholm sowie das kommende Jahr in England zu ver- 


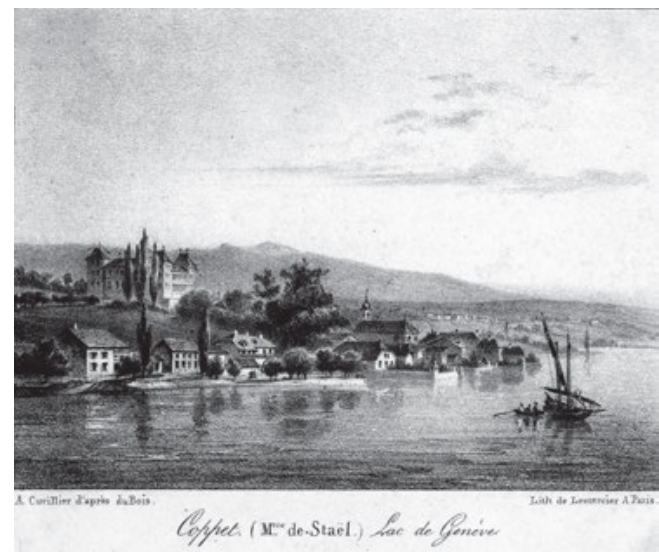

Abb. 44: Das Schloss Coppet am Genfer See.

bringen. Es ist immer wieder faszinierend $\mathrm{zu}$ beobachten, wie die noch junge Frau allerlei Zwangsmaßnahmen gegen ihre Person für ausgedehnte Reisen und ein eigenes Bildungsprogramm produktiv für sich zu nutzen verstand. Nach dem ersten Sturz Napoleons kehrte sie nach Paris zurück, floh aber während der „Hundert Tage“ erneut nach Coppet. 1816 ging sie heimlich zum zweiten Mal die Ehe mit ihrem langjährigen Geliebten Rocca ein, mit dem sie nebenbei ein fünftes Kind hatte. Doch im Februar 1817 erlitt die knapp einundfünfzigjährige Frau, deren Körper durch die Anstrengungen des Exils sowie einen anhaltenden Opiumkonsum geschwächt war, einen schweren Schlaganfall, an dessen Folgen sie am 14. Juli 1817 in Paris verstarb.

Das literarische Schaffen der Madame de Staël ist stark von ihrer Lebensführung geprägt und glänzt durch seine intensiven Berührungspunkte mit vielen Vertretern eines literarischen Feldes, das wohl nur wenige so hautnah kannten wie diese Schriftstellerin, die selbst noch ihre Zeiten im Exil zur Erweiterung ihres literarischen und kulturellen Horizonts intensiv zu nutzen verstand. Ihr Euvre situiert sich innerhalb der Übergangszeit von der französischen Spätaufklärung des 18. Jahrhunderts zur europäischen Romantik; und alle ihre literarischen Schriften weisen deutliche Spuren zahlreicher historischer Erfahrungen auf, welche unverkennbar im Zeichen der radikalen politischen Umwälzungen ihrer Zeit stehen. Bereits 1788/89 erschien ihre erste literaturkritische Arbeit, die sie Jean-Jacques Rousseau widmete und die charakterlichen Besonderheiten des Genfer Bürgers bereits auf die politischen Umwälzungen nach seinem Tode bezog. Auch in diesem Detail zeigt sich einmal mehr, dass eine umfangreichere Arbeit über das 19. Jahrhundert auf die schillernde und verschiedenartigste Reaktionen hervorbringende Gestalt Rousseaus schlechterdings nicht verzichten kann: So haben wir es auch in unserer Vorlesung gehalten! 
Ihren Essai sur les fictions übersetzte 1796 kein Geringerer als Goethe unter dem Titel Versuch über die Dichtungen für Die Horen - eine erste Kontaktaufnahme der Schriftstellerin mit der deutschen Literaturwelt. Wenige Jahre später sollte sie unter anderem Goethe und Schiller in Weimar besuchen. Ihre im Jahr 1800 erschienene literatursoziologische Schrift De la littérature considérée dans ses rapports avec les institutions sociales (Über Literatur in ihren Verhältnissen mit den gesellschaftlichen Einrichtungen) stieß erstmals auf den polemischen Widerstand der napoleonischen Literaturkritik, die ihr zu verstehen gab, dass sie als intellektuelle Frau und Verteidigerin liberaler Prinzipien in Frankreich unerwünscht sei. Sie trat darin auch für eine Öffnung der französischen Literatur für ein germanisch-christliches Europa ein und ebnete dadurch in gewisser Weise den Weg Frankreichs zum Geist der Romantik.

Madame de Staël ließ sich von den Stimmen der offiziellen Literaturkritik in Frankreich nicht beirren und widersetzte sich auch als Frau selbstbewusst: Sie machte ihren Salon in Paris zu einem Hort liberaler Opposition gegen ein zunehmend autoritäres Regime, das freilich die Volksmassen begeisterte - und nicht nur sie. Diese literarischen und soziopolitischen Aktivitäten waren es, die sie zu einer für Napoleon gefährlichen Gegnerin werden ließen. Nach Erscheinen ihres Briefromans Delphine, in den sie ihre Erfahrungen als selbständige Frau mit einigen Reminiszenzen an Benjamin Constant reflektierte, musste sie Paris und später ganz Frankreich binnen kürzester Frist verlassen.

Nur mit allergrößter Hochachtung kann man beobachten, wie für Germaine de Staël das Exil zu einer Chance wurde, nicht nur ihren literarischen Salon nach Coppet zu transferieren, sondern europäisch auszuweiten und $\mathrm{zu}$ einem Zentrum des Kulturaustauschs zu machen. Viele ihrer Positionen sind eine Frucht des Dagegenhaltens gegen die Zeitläufte, gegen bittere Erfahrungen, die sie vor allem mit der französischen Gesellschaft machte - ohne dass dies doch ihre Liebe zu Frankreich in Frage gestellt hätte. Zugleich wurde sie zu einer Begründerin literaturkritischer und -soziologischer, aber auch vergleichender Studien und eröffnete den langen Reigen historiographischer Arbeiten über die Französische Revolution.

Dass ihr vielleicht einflussreichstes Werk De l'Allemagne in Frankreich auf Geheiß Napoleons mitsamt des Manuskripts beschlagnahmt wurde und erst drei Jahre später in London - Schlegel rettete, wie wir noch hören werden, die Druckfahnen - erscheinen konnte, gehört zu den nicht unwichtigen Fußnoten eines bewegten Lebens. Die der Republik Genf entstammende französischsprachige Autorin wurde zu einer der großen Stimmen eines künftigen Europa und einer polyphonen europäischen Literatur. Die zahlreichen autobiographischen Elemente in Corinne ou l'Italie ließen Germaine de Staël auch zu einer der großen weiblichen Schriftstellerinnen werden, welche mit emanzipatorischer Geste nicht 
allein die kulturelle, sondern auch die Geschlechterdifferenz zum Thema ihres Schreibens machten. So konnte die Verfasserin zahlreicher Werke, aber auch einer nachgelassenen Autobiographie, die man unter dem charakteristischen Titel Dix années d'exil veröffentlichte, zu einem Vorbild etwa für Gertrudis Gómez de Avellaneda und viele andere schreibende Frauen werden.

In diesem doppelten Sinne könnte man Madame de Staël, die aus heutiger Sicht als Schweizerin geradezu prädestiniert dafür war, als eine wirkliche Europäerin bezeichnen. Dies nicht nur auf Grund ihrer regen Reisetätigkeit, sondern auch auf Grund ihrer Einsicht, dass die Beschäftigung mit einer einzigen Literatur nicht ausreicht, um sich ein Bild von der Literatur im speziellen und der Kultur im Allgemeinen zu machen. Es wäre freilich hochgradig ungerecht, Germaine de Staël als reine Vermittlerin zu bezeichnen; denn in ihren eigenen literarischen wie literaturtheoretischen sowie literaturkritischen Schriften entfaltete sie eine Vielzahl von Ansatzpunkten und kreativen Überlegungen, die sie auch zu einer Autorin in Scharnierstellung zwischen dem 18. und dem 19. Jahrhundert machen.

Das Exil ist sicherlich aus menschlich-individueller Sicht eine schreckliche, zerstörerische Erfahrung. Doch zeigt sich nicht allein am Beispiel von Esteban Echeverría und einer Vielzahl noch zu analysierender Schriftsteller des lateinamerikanischen 19. Jahrhunderts, aber eben auch bei der Autorin von De l'Allemagne, dass es oftmals Entwicklungen im interkulturellen Bereich in Gang setzt. Diese sind von ungeheurer und langfristiger kollektiver Bedeutung, wären aber ohne die persönliche Erfahrung des Exils vielleicht niemals in Gang gesetzt worden. Aus dieser Perspektive ist es bedeutsam, dass Germaine de Staëls größte literarische Aktivität und Kreativität in die Regierungszeit Napoleons und damit in eine postrevolutionäre Phase fiel, die von einem Mann beherrscht wurde, zu dem sie anfangs vergeblich Kontakt gesucht hatte, der sie umgekehrt mit seinem Hass und Argwohn bis in alle Ecken Europas verfolgte. Selbst während seines Russlandfeldzugs ließ er sich regelmäßig von den Überwachungen der Madame de Staël berichten. Napoleon maß seiner Gegenspielerin im intellektuellen wie literarischen Feld eine überraschend große Bedeutung zu, was die Eminenz ihrer literarischen Gestalt zweifellos betonte. Zugleich ließ er über die historische Situation Frankreichs verlautbaren, dass die Französische Revolution nunmehr beendet sei.

Diese Einschätzung mag für die Bereiche Geschichte und Politik sicherlich zutreffend gewesen sein. Die literarisch-ästhetische Revolution jedoch, so dürfen wir formulieren, stand Frankreich und den meisten europäischen Ländern noch bevor - auch wenn wir dieses Panorama aus einem anderen Blickwinkel mit Chateaubriand bereits näher betrachtet haben. Schon in den letzten Jahren des Ancien Régime und viel mehr noch während Revolution und Empire war die Millionärstochter eine der bekanntesten und zugleich umstrittensten Frauenfiguren französischer Zunge. Ihre Feindschaft gegenüber Napoleon machte sie zusammen 
mit ihren grundlegenden Schriften weit über die Grenzen Frankreichs hinaus berühmt.

Germaine de Staëls Geschicklichkeit im Umgang mit Menschen, in der Konversation und in der Organisation eines Salons - zudem eines literarischen Zirkels - waren sprichwörtlich. Auf ihrem Anwesen in Coppet baute sie sich nicht nur einen Rückzugsort, sondern einen dauerhaften Gesprächskreis und eine politisch-literarische Plattform auf, mit deren Hilfe sie weit über den französischsprachigen Raum ausstrahlen konnte, zugleich aber auch direkt nach Frankreich hinein wirkte. Die Zensur- und Eindämmungsmaßnahmen Napoleons belegen, wie effizient das geschickte Vorgehen der Genferin war und wie sehr sie das intellektuelle wie literarische Feld Frankreichs beeinflusste. Coppet wurde rasch zu einem der wichtigsten literarischen Brennpunkte Europas.

$\mathrm{Zu}$ ihrem Reich gehörten als Stützen unter anderem Benjamin Constant, Sismondi, August Wilhelm Schlegel oder Madame Récamier; daneben kamen viele Gäste vorbei, die zeitweilig im Schloss wohnten, deren Besuch auf dem Anwesen jedoch nicht selten von den französischen Behörden behindert wurde. Literatur und Politik waren die beiden großen Themenbereiche, die in den Konversationen von Coppet, aber auch in den Schriften von Madame de Staël eine unauflösliche Verbindung miteinander eingingen. Man darf Germaine de Staël folglich ohne jede Übertreibung und avant la lettre als die große Intellektuelle der europäischen Geistesgeschichte begreifen, der es gelang, zwischen Aufklärung und Romantik eine zweifache Ausrichtung der Literaturen Europas zu bewerkstelligen.

Denn nicht von ungefähr gilt sie als Begründerin zweier literaturwissenschaftlicher Disziplinen: zum einen der (in Deutschland niemals besonders beliebten) Literatursoziologie, indem sie Literatur und Gesellschaft auf eine theoretisch reflektierte Weise direkt miteinander in Verbindung brachte. Zum anderen inaugurierte sie die Vergleichende Literaturwissenschaft, die Komparatistik, da sie stets versuchte, Literatur nicht als Nationalliteratur - das Konzept entstand in jenen Jahren -, sondern jenseits nationaler und kultureller Grenzen zu verstehen und das eigene Schaffen gerade aus dem Kontrast zum Anderen heraus verständlich $\mathrm{zu}$ machen.

Insoweit ließe sich mit guten Gründen sagen, dass Madame de Staël als Literaturtheoretikerin - wie wir heute sagen würden - bestens vorbereitet war, die große interkulturelle Bedeutung literarischen Schaffens $\mathrm{zu}$ begreifen und darzustellen. Es mag sein, dass sie in späterer Zeit gerade auch aufgrund dieser vermittelnden und interkulturellen Position - und selbstverständlich auch aufgrund ihrer Situation als Frau - mancherlei Verleumdungen und einem doch nie ganz gelungenen Prozess der Verdrängung preisgegeben wurde. Doch diese selbstbewusste Grande Dame der Literatur hat all diese Anfeindungen überlebt, wie sie auch zu Lebzeiten dem autoritären System Napoleons ihren Widerstand erfolg- 
reich entgegensetzte. Gerade in den letzten Jahrzehnten, im Umfeld der Gender Studies, aber auch weit über diese hinaus, hat das wissenschaftliche Interesse an Madame de Staël wieder deutlich zugenommen und kommt in einer Reihe neuerer Dissertationen nicht zuletzt auch im deutschsprachigen Raum zum Ausdruck.

Ihre erste große literaturtheoretische Schrift ist ohne jeden Zweifel der bereits kurz erwähnte und im Jahr 1800 - also zusammen mit dem neuen Jahrhundert der Literatur - erschienene Band De la littérature. Dessen voller Titel lautet De la littérature considérée dans ses rapports avec les institutions sociales, ein Buch von enormer Wirkung, mit dem wir uns aus Zeitgründen freilich nicht allzu lange beschäftigen können. Wissenschaftsgeschichtlich betrachtet handelt es sich um einen Gründungstext literatursoziologischer Studien. Die Grundthese dieser Arbeit besagt letztlich nichts anderes, als dass die Geschichte einer Literatur nur dann adäquat untersucht und begriffen werden könne, wenn man sie mit dem gesellschaftlichen und moralischen Zustand eines Volkes oder einer Nation, also mit der Gesellschaft ihrer Zeit in Verbindung bringt.

Wenn es auch gerade in Montesquieus Schriften, welche die Staël sehr prägten, eine starke Vorläuferschaft gibt, die im Übrigen in zweiter Linie ebenfalls Marmontel, Lessing oder Herder miteinschließt, so ist diese These doch niemals zuvor in einer solchen Breite durchgeführt und auf literarische Entwicklungen angewandt worden. Gerade der erste Satz von De la littérature ist, wie schon Erwin Koppen meinte, ${ }^{2}$ fast wortwörtlich von Marmontel übernommen worden, den sie in einer Fußnote neben Voltaire und La Harpe freilich sofort als Bezugsautor nannte. Dieser Satz erste gab das Programm der Germaine de Staël vor, und so möchte ich ihn Ihnen auch nicht vorenthalten. Es handelt sich eigentlich um den ersten Abschnitt ihres „Discours préliminaire“ und er beginnt, auch dies vielleicht nicht ganz zufällig, mit dem kleinen Wörtchen „Je“, also mit dem Ich der Autorin:

Ich habe mir vorgenommen, den Einfluss der Religion, der Sitten und der Gesetze auf die Literatur zu untersuchen und nach dem Einfluss der Literatur auf die Religion, die Sitten und die Gesetze zu fragen. In französischer Sprache gibt es Abhandlungen über die Kunst des Schreibens und die Prinzipien des Geschmacks, welche nichts zu wünschen übrig lassen; aber mir scheint, dass man die moralischen und die politischen Gründe nicht ausreichend untersucht hat, welche den Geist der Literatur modifizieren. Man hat, so scheint mir, noch nicht in Betracht gezogen, wie sich die menschlichen Fähigkeiten graduell durch in allen Gattungen berühmte Werke entwickelt haben, welche seit Homer bis in unsere Tage verfasst wurden. ${ }^{3}$

2 Vgl. Koppen, Erwin: Madame de Staël. In: Lange, Wolf-Dieter (Hg.): Französische Literatur des 19. Jahrhunderts. I: Romantik und Realismus. Heidelberg: Quelle \& Meyer 1979, S. 50-69.

3 Staël, Germaine de: De la littérature : considéré dans ses rapports avec les institutions sociales. Paris: InfoMédia Communications 1998, S. 15. 
Sie können an dieser Passage ohne weiteres erkennen, dass es Madame de Staël um eine literaturgeschichtliche Betrachtungsweise geht, die die Entwicklung der Literatur von Homer, also von den Anfängen der griechischen Antike, bis in die damalige Gegenwart, also bis in die Jahre der Französischen Revolution hinein zu verfolgen und $\mathrm{zu}$ analysieren sucht. Bei einer derartigen Untersuchung entsteht ganz zweifellos nicht nur ein vergleichendes Bild der Literaturen, sondern auch eine Theorie im Sinne einer Allgemeinen Literaturwissenschaft, so dass Madame de Staël auch in dieser Hinsicht sehr wohl als eine der großen Gründungsfiguren der Zunft bemüht werden darf.

Aufschlussreich ist in diesem Zusammenhang zum zweiten, dass die in Paris geborene Autorin die Beziehungen zwischen Literatur und außerliterarischen Instanzen, von denen sie Religion, Sitten und Gesetze als Bezugspunkte nennt, keineswegs als Einbahnstraße begreift. Dies insoweit, als dass die Gesellschaft auf die Literatur eingewirkt haben dürfte und so das Verhältnis beider als wechselseitiger Prozess verstanden werden kann. Der Literatur wird nämlich die Fähigkeit zugewiesen, Religion, Sitten und Gesetze ihrerseits zu beeinflussen. Mit diesem schlichten Argument wird der Literatur - und implizit natürlich auch den Literatinnen und Literaten - eine gesellschaftsverändernde Funktion zuerkannt, die Möglichkeit also, mit Hilfe ihrer Schriften Einfluss auf die Gesellschaft und deren Verfasstheit zu gewinnen. Und Madame de Staël ließ sich nicht lange bitten, diese gesellschaftsverändernde Wirkung von Literatur auch selbst unter Beweis zu stellen.

Wenn die Literatur aber andererseits von ihren jeweiligen außerliterarischen Kontexten her beeinflusst werden kann und beeinflusst wird, dann ist unverkennbar deutlich, dass es keine übergeordneten, ein für alle Mal geltenden Normen und Paradigmen geben kann, die überzeitlichen Geltungsanspruch für sich reklamieren dürften. Gewiss ist diese Fragestellung bereits Ende des 17. Jahrhunderts in der berühmten „Querelle des Anciens et des Modernes“ aufgeworfen worden im Zusammenhang mit der Frage, ob die antiken Normen Gültigkeit und Modellanspruch auch in der aktuellen Zeit der „Modernes“ haben dürfen. Doch stellt sich diese Frage im Kontext der Madame de Staël und damit zugleich im Kontext einer postrevolutionären Literaturauffassung neu und auf ganz andere Weise.

Denn in der Tat hat die Französische Revolution vieles hinweggefegt, was nichts anderes heißt, als dass sie zugleich viele Möglichkeiten für die Zukunft eröffnete; und der Aufbau einer neuen Literatur schien Madame de Staël stets von größter Notwendigkeit und zugleich auch Evidenz zu sein. Die Frage war nur, wie diese künftige Literatur aussehen würde und aussehen sollte! Der Geist der Literatur wird für Germaine de Staël von außerliterarischen Faktoren mitgeprägt; eine Tatsache, die gerade auch auf die Einsicht wirken wird, dass jedes Land, jede 
Nation ihre eigene Entwicklung, ihre eigenen Schwerpunkte und Charakterzüge in der literarischen Praxis entwickeln wird.

Die Folgen dieser Einsicht liegen auf der Hand: Nationalliteratur wird denkbar - ganz im Herder'schen Sinne - als ein Ausfluss des Volksgeistes, als eine von einem bestimmten Volk, einer bestimmten Nation her grundlegend geprägter Bereich des Eigenen, der sich von anderen Bereichen, von anderen Literaturen abgrenzen lässt. Madame de Staël freilich wäre nicht die Erbin der „Lumières“ und damit der „République des Lettres“ des 18. Jahrhunderts, die sie tatsächlich war, würde sie hier einer nationalistischen Perspektivierung und Schlussfolgerung durch eine komparative oder komparatistische Perspektivierung nicht entschieden den Wind aus den Segeln nehmen. Die Veränderbarkeit von Literatur schließt ihre regionale Differenzierung nicht weniger ein als ihre ergebnisoffene historische Entwicklung: Dies sind Vorstellungen, die im Grunde das Literaturkonzept der Moderne in ganz entscheidendem Maße prägten; und mit der Moderne selbstverständlich auch das Literaturkonzept der Romantik.

Für den weiteren Verlauf von De la littérature ist freilich entscheidend, dass Madame de Staël ihre Ausführungen nicht auf bloße Theorie beschränkte, sondern Theorie und Anwendung miteinander verband. Literatur ist nunmehr den Einflüssen von Zeit und Raum unterworfen, also auch dem Wechsel der Zeiten und den geographischen Bedingungen - eine Einsicht, die gerade auch mit Blick auf unsere Vorlesung und die darin behandelten Literaturen beider Welten von größter Bedeutung ist. Dabei geht es nicht darum, dass die Verfasserin von De l'Allemagne nicht die Literaturen jenseits des Ozeans im Auge hatte oder auch im Auge haben konnte. Doch auch ohne eine Einbeziehung der amerikanischen Literaturen brachte die Romantik nicht nur höchst unterschiedliche literarische Bewegungen und Traditionen hervor, sondern reflektierte diese auch als solche. Sie entwickelte also von Beginn an - mit Blick auf Madame de Staël könnte man sagen, vielleicht noch sogar vor ihrem eigentlichen Beginn - eine Theorie dieser Verschiedenheit, welche von Zeit und Raum und der Kombination von beiden, der Mobilität, abhängt.

Eine Grund- und Lieblingsidee Germaine de Staëls hat sie von der Aufklärung und speziell von Jean-Jacques Rousseau, ihrem Genfer Landsmann, übernommen, mit dessen Werken sie natürlich aufs Beste vertraut war, dem sie ihre erste literarische Schrift gewidmet hatte und der bekanntlich diesen Neologismus auch geschaffen hatte: Es ist die Idee der „perfectibilité“. Diese „Perfektibilität“ zielt auf eine sich immer mehr vervollkommnende Geschichte der Menschheit und insbesondere auf die Fähigkeit des Menschen, sich ständig weiter zu perfektionieren. Dieser im Grunde anthropologische Befund wird auf den Bereich der Literatur übertragen, ohne dass Perfektibilität dabei als glatter, linear verlaufender Prozess gedacht werden sollte. Jede Epoche, so heißt es bei Madame 
de Staël, trage den Geist der vorangegangenen Epoche in sich, so dass sie über einen größeren literarischen Fundus als alle vorangegangenen verfüge. Diese Vorstellung ließe sich sehr gut mit unserer heutigen Auffassung von Intertextualität verbinden, welche davon ausgeht, dass bereits das Gilgamesch-Epos intertextuell auf früheren Texten aufruht und wir bei einem aktuellen Roman sehr wohl die intertextuellen Linien noch heute quer durch die Epochen bis zu diesem Epos aus Mesopotamien ziehen könnten: Denn Intertextualität ist das schlagende Herz der Literaturen der Welt.

Ein weiterer wichtiger Punkt, der uns aus heutiger Sicht recht modern anmutet, betrifft die Tatsache, dass die erfolgreiche „Salonière“ einen offenen Literaturbegriff pflegte, der nicht nur die „Belles-Lettres“, sondern im Grunde alles Schriftgut mit Ausnahme der naturwissenschaftlichen Schriften mitberücksichtigte. Es ging Madame de Staël mithin um alle Formen schriftlichen Ausdrucks menschlichen Denkens, ein fürwahr weites Feld, das einen erhellenden Lichtschein wirft auf die nun ins Wanken geratende Hierarchie der verschiedenen literarischen Gattungen und auf jene Gattungsmischung, die in der Romantik in Europa wie in den Amerikas eine so wichtige Rolle spielen sollte. Das streng geordnete hierarchische System kanonisierter Gattungen des Ancien Régime war in deutlicher Auflösung begriffen, auch wenn sich die Reden der französischen Revolutionäre noch immer an der klassischen Rhetorik orientierten und berauschten.

Schon in De la littérature öffnete Germaine de Staël den Blick ihrer Zeitgenossen - und nicht nur ihrer Landsleute - über den Bereich der französischen Literatur, die sie sicherlich noch immer als führend betrachtete, hinaus und verwies auf das wachsende Gewicht der Literaturen des Nordens, unter denen sie in erster Linie die Literaturen Englands, Deutschlands, Dänemarks und Schwedens verstand. An diesem Punkt tritt nun eine Gegensätzlichkeit auf, die wir ebenfalls im Kontext der Klimatheorie bereits bei Montesquieu finden können, die aber dem Bereich der Literaturen des Südens nun den Bereich des Nordens entgegenstellt und damit den unterschiedlichen Regionen Europas eine Art Zweitaktmotor unterschiebt. Ganz so, wie Amerika in zwei verschiedene, einander entgegengesetzte Teile zerfallen wird, teilte sich bei Madame de Staël bereits Europa in zwei klar voneinander geschiedene Räume auf: den Süden und den Norden.

Es handelte sich dabei um eine Zweiteilung, welche letztlich auf eine gegenseitige Ergänzung und vor allem auf eine komplementäre Beziehung hinauslief. Folgen wir noch einmal Wolfgang Koppen, so war die Idee eines literarischen Nord-Süd-gegensatzes Madame de Staëls eigene Erfindung, die sie wenige Jahre später in De l'Allemagne weiter vertiefen sollte. Dass sich diese geokulturelle Zweiteilung nachfolgend auch mit Blick auf andere Kontinente popularisierte, kann zweifellos auf die große Ausstrahlungskraft der frankophonen Intellektuellen avant la lettre zurückgeführt werden. Freilich: Die Einbeziehung der Literaturen 
des Nordens war zweifellos eine Provokation des französischen Selbstbewusstseins! Und als eine solche wurden die Veröffentlichungen der Staël dann auch von den Zeitgenossen in Frankreich gelesen. Frankreich - dies musste für jeden, der den Thesen Madame de Staëls folgen wollte, fürderhin feststehen - war nun nicht länger der Nabel der literarischen Welt. Es soll französische Kultusbeamte geben, bei denen sich diese Einsicht bis heute noch nicht herumgesprochen hat. Aber lassen wir diese unschuldige Polemik ...!

Madame de Staël führte ihre Überlegungen in dieser Richtung noch weiter, denn sie zeigte in De l'Allemagne unverkennbar die Grenzen und Begrenztheiten des literarischen Frankreich anhand eines Vergleichs mit Deutschland auf. Gleichzeitig entwickelte sie mit dieser veränderten Perspektive ein neues Deutschlandbild, das in der Folge bis in die beginnenden kriegerischen Auseinandersetzungen der zweiten Hälfte des 19. Jahrhunderts und bis in die nationale Konstituierung Deutschlands Bestand haben sollte. Dabei scheint mir, dass dieses neue Bild als ,Land der Dichter und Denker' auch in Deutschland selbst lange Zeit dominant war oder fortwirkte: Das aus der Fremde gespiegelte Bild wurde zum Selbstbild der Deutschen, ein Fremdbild als Selbstbild von beeindruckender Dauerhaftigkeit, das auch heute noch immer wieder einmal präsent ist.

Germaine de Staël hatte mit ihrem neuen Werk nicht nur kurzfristig, sondern auch langfristig großen Erfolg. Sicherlich war De l'Allemagne eine literarische Provokation und in gewissem Maße auch ein Skandalerfolg, aber nicht an die zeitlichen Grenzen eines solchen „succès de scandale“ gebunden. Die Zensur Napoleons verbot das Buch rasch; und De Staël begriff die sich ihr bietende Gelegenheit, dieses Verbot für sich nutzbar zu machen und sich als Gegnerin des „Empereur“ zu profilieren. Denn die einzige Rettung der Zensierten ist es, die Zensur selbst ins öffentliche Rampenlicht zu zerren.

Sie konnte auf ein Verfahren zurückgreifen, das eine Vielzahl französischer Aufklärer, die sie im Hause ihres Vaters als kleines Mädchen noch selbst persönlich kennengelernt hatte, für sich erfolgreich zu nutzen suchten: die Selbststilisierung zur verfolgten Tugend, zur „,vertu persécutée“. Wir hatten dieses Verfahren bereits bei Fray Teresa de Mier in seiner Wirkungsweise kennengelernt. Auch Germaine de Staël praktizierte es mit großem Erfolg, etwa durch das Vorschalten eines auf Oktober 1813 in London datierten nachgeschobenen Vorworts, in welchem sie sich über die Zensurbehörden Napoleons und dessen Polizeiminister höchst selbst lustig machte. De l'Allemagne ging im April des Jahres 1810 erstmals in den Druck, wurde dann aber sofort beschlagnahmt und das Manuskript sichergestellt, was im Prinzip einem völligen Ausradieren dieses Werkes gleichkam. Doch August Wilhelm Schlegel brachte im Mai 1811 die Korrekturfahnen des Textes in Sicherheit, um das Werk vor dem vernichtenden Zugriff der napoleonischen Polizei zu schützen. Im Sommer 1813 erschien dann das Werk in französischer Sprache in 
London und wurde zu einem großen, nachhaltigen, in ganz Europa wirksamen Erfolg.

Der gewählte Blickwinkel von De l'Allemagne ist von Beginn an kulturgeschichtlich und kulturtheoretisch. Dies zeigt bereits der erste Abschnitt der dem Werk vorangestellten „Considérations générales“, die weniger durch ihre Originalität als durch ihre Präzision und Durchschlagskraft beeindrucken:

Die führenden Nationen Europas lassen sich in ihrem Ursprung auf drei verschiedene große Rassen zurückführen: die lateinische Rasse, die germanische Rasse und die slawische Rasse. Die Italiener, die Franzosen, die Spanier haben von den Römern ihre Zivilisation und ihre Sprache erhalten; die Deutschen, die Schweizer, die Engländer, die Schweden, die Dänen und die Holländer sind teutonische Völker; und unter den Slawen schließlich nehmen die Polen und die Russen den ersten Rang ein. Jene Nationen, deren geistige Kultur von lateinischem Ursprunge ist, sind seit längerer Zeit zivilisiert als die anderen; sie haben zumeist die geschickte Klugheit der Römer in der Führung der Geschäfte dieser Welt geerbt. Gesellschaftliche Institutionen, welche auf die heidnische Religion gegründet waren, sind bei ihnen der Etablierung des Christentums vorausgegangen; und als die Völker des Nordens sie eroberten, haben diese Völker in vielerlei Hinsicht die Sitten der Länder angenommen, die sie besiegten.

Diese Beobachtungen müssen zweifellos gemäß der Klimate, der Regierungen und der Tatsachen jeder einzelnen Geschichte modifiziert werden. ${ }^{4}$

In diesem klar angelegten Eingangstor zu ihrem Band De l'Allemagne sieht Germaine de Staël Europa gleichsam aus drei verschiedenen Teilen sich zusammensetzend, wobei ihr Begriff der „race“ ein vorwiegend kultureller, in keiner Weise rein biologischer und schon gar nicht rassistischer Begriff ist. Wir können an dieser Stelle auch mit Blick auf die Amerikas erneut festhalten, dass in den lateinischen Völkern diesseits und jenseits des Atlantik der Begriff „race“ oder „raza“ vorwiegend kulturell geprägt ist.

Spannend ist übrigens, dass Alexander von Humboldt im dritten Band des Berichts von seiner Reise in die amerikanischen Tropen, also seiner Relation historique, eben diese Aufteilung auf Amerika übertrug, indem er ein lateinisches von einem germanischen und einem slawischen Amerika unterschied und damit implizit auch eine Gleichstellung mit Europa betrieb. Dass seine Formulierung von einer „Amérique de l'Europe latine“ später in einem veränderten politischen Kontext ohne jeden Verweis auf ihn wiederaufgenommen wurde und $\mathrm{zu}$ der Bezeichnung „Lateinamerika“ führte, möchte ich an dieser Stelle lediglich kurz betonen, ohne dies näher auszuführen.

4 Staël, Germaine de: De l'Allemagne [1810]. Paris: Librairie Stéréotype 1814, Bd. 1, S. 1 f. 
Die Überlegungen von Madame de Staël laufen trotz ihrer grundsätzlichen Dreiteilung auf eine scharf herausgearbeitete Opposition zwischen dem lateinischen und dem germanischen Europa hinaus. Die große Literatur- und Kulturtheoretikerin stellte in diesem Zusammenhang ein Europa des Südens - des „Midi“ - einem Europa des Nordens entgegen, was die vielleicht nachhaltigste Unterscheidung in ihrem einflussreichen Denken darstellt. Ihre Theorien laufen immer wieder auf Oppositionen, Antagonismen und scharfe Kontraste hinaus, welche dann freilich in eine Entwicklungsgeschichte wechselseitiger Beeinflussung und in gewisser Weise in einen dialektischen Prozess der Herausbildung komplexerer Einheiten überführt werden. Doch es war gerade diese Ausgangslage, welche die Ansichten von Germaine de Staël so griffig und damit leicht adaptierbar machte.

Neben den diskursiven Oppositionspaaren von Frankreich und Deutschland sowie von Norden und Süden gibt es bei dieser Schriftstellerin als weitere grundsätzliche Opposition - wen würde es verwundern - die Unterscheidung zwischen Männern und Frauen, die sich quer durch De l'Allemagne zieht und zu überraschenden, bisweilen etwas bizarr anmutenden Theorien führt. So verteidigt sie etwa die Anschauung, dass die französische Galanterie gerade nicht - wie dies oft behauptet werde - Frankreich zu einem Paradies der Frauen mache, sondern die sexuelle Libertinage verstärke, unter der besonders die Frauen litten. Im Gegensatz dazu sperrten die Türken ihre Frauen ein, womit sie ihnen bewiesen, wie nötig sie sie doch hätten.

Auch im weiteren Vorgehen ist eine scharfe Argumentation ausgehend von Oppositionen stets bemerkbar. So wird Süddeutschland Norddeutschland gegenübergestellt, was eher zum Vorteil des letzteren gereicht. Diese Zweiteilung entbehrt aus Sicht der Genfer Pariserin nicht einer gewissen Logik, denn nur von den Wäldern und Nebelschwaden des Nordens her war ein wirklicher Gegensatz auch klimatisch-ambientaler Art gegenüber Frankreich aufzubauen: Die Klimatheorien Montesquieus wirkten in ihr fort.

Diese geoklimatischen Überlegungen beherrschen dann auch das erste Kapitel des ersten Teils, in welchem es um den „aspect de l'Allemagne“, um das physisch-geographische Erscheinungsbild Deutschlands geht, das unzweifelhaft von ausgedehnten Wäldern beherrscht wird. Klar und deutlich wird darauf hingewiesen, dass nach der Zeit der Völkerwanderung noch nicht der gesamte Naturraum in Kulturraum umgewandelt wurde, so dass es auf diesem Gebiet bei aller Majestät der Landschaften - doch noch immer erhebliche Restbestände der unmittelbaren, vom Menschen noch nicht beeinträchtigten Natur gebe. Ja, die germanischen Wälder: Sie haben schon im Römischen Reich seit Tacitus das Germanenbild beherrscht! Und eben so verlaufen die literarischen Traditionen. Sie dominieren noch im 19. Jahrhundert ein Deutschlandbild, das dann am 
deutschen Schicksalsfluss entlang aufgebaut wird - dem Rhein. Dessen Majestät darf natürlich auch in Madame de Staëls Betrachtungen über Deutschland nicht fehlen!

Bemerkenswert ist die große Fülle an kulturtheoretischen Überlegungen, welche die kluge und aufmerksame Französin Schweizer Herkunft mit Blick auf Deutschland entwickelte. In vielfachem Sinne fundamental und selbst noch in unseren Corona-Zeiten - wenn auch nun unter dem Stichwort „Länderhoheit“ heiß diskutiert ist ihre Feststellung, die den fehlenden Zentralismus in Deutschland angeht. Mit Blick auf das damalige, aber auch noch aktuelle Deutschlandbild sollten wir uns diese Überlegungen einmal näher ansehen:

Da es keinerlei Hauptstadt gibt, wo sich die gute Gesellschaft ganz Deutschlands versammeln könnte, übt der gesellschaftliche Geist dort wenig Macht aus; das Reich des guten Geschmacks und die Waffe des Lächerlich-Machens bleiben einflusslos. Die Mehrzahl der Schriftsteller und Denker arbeitet in der Einsamkeit oder nur von einem kleinen Zirkel umgeben, den sie beherrschen. Sie lassen sich, ein jeder für sich, zu allem hinreißen, was ihnen eine zwanglose Einbildungskraft einflüstert; und wenn man in Deutschland Spuren einer Beeinflussung durch Moden bemerken kann, so betrifft dies das Begehren, das ein jeder verspürt, sich von allen anderen gänzlich verschieden zu zeigen. In Frankreich hingegen bemüht sich jedermann, das zu verdienen, was Montesquieu von Voltaire sagte: $\mathrm{Er}$ besitzt mehr als jeder andere den Geist, den alle Welt hat. Die deutschen Schriftsteller würden lieber noch die Ausländer als ihre Landsleute nachahmen.

In der Literatur wie in der Politik haben die Deutschen zu viel Respekt vor den Ausländern und nicht genügend nationale Vorurteile. Dies ist eine Qualität bei den Individuen, welche die Verleugnung seiner selbst gepaart mit der Wertschätzung der anderen erzeugt; doch der Patriotismus der Nationen muss egoistisch sein. [...] die Deutschen sind Sachsen, Preußen, Bayern, Österreicher; aber der germanische Charakter, auf den man die Stärke von allen gründen müsste, ist so zerstückelt wie das Land, welches so viele verschiedene Herren besitzt. $^{5}$

Auf diesen Seiten entsteht ein Deutschlandbild, das uns noch heute nicht ganz kalt lassen kann. Denn vieles aus diesem Fremdbild, das aus einer lateinischen, mithin romanischen Perspektivik und aus dem Vergleich mit Frankreich aufgenommen wurde, ist sehr rasch - und weit über die gerne gehörte Rede vom ,Land der Dichter und Denker، hinaus - zu einem Selbstbild der Deutschen geworden. Vergessen Sie dabei bitte nicht, dass dies ein Deutschlandbild ist, welches noch vor dem Aufkommen eines starken Nationalismus in deutschen Landen gerade gegen die napoleonische, also französische Fremdherrschaft entstand!

Sicherlich zeigt gerade der zweite Absatz, wie sehr sich jenes Deutschland im weiteren Verlauf des 19. Jahrhunderts verändern sollte, das Madame de Staël

5 Staël, Germaine de: De l’Allemagne [1810]. Paris: Librairie Stéréotype 1814, Bd. 1, S. 16 f. 
zum damaligen Zeitpunkt bereiste und dessen nationaler und nationalistischer Patriotismus durch jenen Napoleon und seine Kriege angestachelt wurde, als dessen unversöhnliche Gegnerin Germaine de Staël bis zu ihrem Tode auftrat. Auch wenn sie recht jung starb, hatte sie immerhin das Glück, den ersten wie den definitiven Sturz Napoleons vor ihrem Tod noch miterleben zu dürfen. Doch die Problematik des in Deutschland fehlenden Zentrums, die in verschiedenen Stufen immer wieder in De l'Allemagne beleuchtet wurde, hatte nicht nur Rückwirkungen auf ein föderales politisches System, sondern auch auf die nicht zu unterschätzende Krise einer nationalen Identitätskonstruktion, welche in diesem Jahrhundert virulent wurde.

Wenn einerseits diese Frage einer offenen Identität mit „germanisch“ beantwortet wurde, wie es noch heute die Bezeichnung „Germanistik“ anzudeuten scheint, dann verwies Madame de Staël andererseits doch sehr hellsichtig auf all jene Gewohnheiten, welche eine Zersplitterung des deutschen Geisteslebens auf der Ebene des intellektuellen Habitus mit sich brachte. Aus dem fehlenden Zentrum ergab sich eine Vereinzelung und Zersplitterung nicht allein im politischen, sondern auch im literarischen sowie kulturellen Bereich, eine intellektuelle Aufsplitterung und Atomisierung in unterschiedlichste kleine Zirkel, die auf das gesamte literarische und intellektuelle Feld Deutschlands durchschlugen. Denn die Deutschen seien vor allem bemüht, sich voneinander zu unterscheiden und sich voneinander abzugrenzen: eine Aufspaltung, die wir etwa auf Universitätsebene noch heute und freilich mit keineswegs nur negativen Entwicklungen beobachten können. Der Unterschied gegenüber Frankreich, das für die Staël ständiger Vergleichspunkt war, ist freilich auch noch heutzutage frappierend.

Folgen wir Germaine de Staël, so denken sich die deutschen Dichter und Denker in ihren Studierstuben die Welt aus und entwickeln Vorstellungen, die sie hernach dann nicht im lockeren Salongespräch auf die Probe stellen können. Die Gesellschaft tritt nicht mit der Waffe des Lächerlich-Machens und ,Ridikülisierens‘ auf, so dass ein gesellschaftliches Korrektiv fehlt. Die Deutschen ließen vielmehr ihrer Einbildungskraft - und diese sei ihre eigentliche Stärke und Veranlagung - freiesten Lauf, was bisweilen zu bizarren Resultaten führe. Hätte es einen Kant in Königsberg am Pregelflusse gegeben, wäre er ständig in den Pariser Salons zur Diskussion seiner philosophischen Thesen gewesen? Das Land der Dichter und Denker ergänzt hier das Land der Wälder und Flüsse, und alles erscheint noch immer so vereinzelt und gesellschaftsfern, wie es einer in Frankreich sozialisierten gebildeten jungen Frau, die als kleines Mädchen schon an den Salons ihrer Mutter teilnehmen durfte, erscheinen mochte.

In vielerlei Hinsicht ist die Frage der Konversation und der geselligen Gemeinschaft - die Frage des Salons also - als funktionale Einheit der Kulturverbreitung einer Gesellschaft für Madame de Staël von ausschlaggebender Bedeutung. Auf 
eben diesem Gebiet sieht sie auch die größten Probleme für die kulturelle Entwicklung des Landes. Aber gab es nicht literarische und andere Salons in dem damals zwar noch provinziellen, aber langsam erwachenden Berlin jener Jahre? Waren dort nicht gerade die jüdischen Salons von großer Bedeutung? Wir werden auf diese Welt der jüdischen „Salonières“ etwas später einen kurzen Seitenblick werfen, fahren jetzt aber fort mit unserer Beschäftigung mit De l’Allemagne.

Es fehlten, so bemängelte die Verfasserin, immer wieder die vermittelnden Instanzen innerhalb der Gesellschaft Deutschlands. Es gebe keine Verbindung zwischen den Regionen und einem Zentrum, keine Verbindung zwischen der Spitze der Gesellschaft und ihren mittleren und unteren Schichten, keine Verbindung zwischen den großen Universitäten und der Bildung des gemeinen Volkes. Es bestand auch keine Verbindung zwischen den großen Philosophen und ihren Lesern, und letztlich auch keine zwischen Frauen und Männern, die im provinziellen deutschen Ständestaat weitgehend getrennt voneinander lebten.

Genau an dieser Stelle aber zeigte sich die wahre Aufgabe der Frauen im Sinne Madame de Staëls: Sie stellen die Entwürfe der Männer auf die Probe, sie vermitteln zwischen den unterschiedlichsten gesellschaftlichen und bildungsmäßigen Gegensätzen! Auch stellen vor allem sie eine gesellschaftliche Öffentlichkeit her, in welcher die einzelnen Ideen auf ihre Wirksamkeit geprüft werden können, und sie sorgen dafür, dass Räume entstehen, in welchen sich die Welt der Frauen und die der Männer begegnen. In Deutschland aber, so bemängelt sie etwa in ihrem Kapitel über Berlin, sei die Gesellschaft der Frauen mit derjenigen der Männer kaum amalgamiert, sondern noch immer radikal von ihr getrennt.

Diese Problematik schlage auf alle anderen Bereiche durch, denn gesellschaftliches Leben - vom guten Geschmack ganz zu schweigen - bildet sich, dies wusste die Erbin der Aufklärung, allein durch und in der Öffentlichkeit. Eben dies aber sei in Deutschland nicht der Fall. Die sich daraus ergebende Einschätzung des deutschen Geistes beziehungsweise des Geistes in Deutschland war bei der Staël durchaus ambivalent.

Ich möchte Ihnen dies gerne am Beispiel des achtzehnten Kapitels über die deutschen Universitäten vorführen. In ihm machte Germaine de Staël klar, dass diese sich für sie im Norden befanden. Nein, nicht, was Sie jetzt denken: Berlin besaß zum damaligen Zeitpunkt noch keine Universität, denn die Uni, auf welche die preußischen Staatsbürger gehen durften, hieß Viadrina und lag in Frankfurt an der Oder! Damit ging eine implizite Abwertung der süddeutschen, katholischen Universitäten einher, was man in Heidelberg, Tübingen oder Freiburg bis heute nicht ganz verschmerzt hat. Wie dem auch sei, wurde das kulturelle Umfeld des deutschen Gelehrten von ihr doch nicht uninteressant beschrieben: 


\begin{abstract}
Der ganze Norden Deutschlands ist voll der gelehrtesten Universitäten Europas. In keinem Land, selbst nicht in England, gibt es so zahlreiche Mittel, sich zu bilden und seine Fähigkeiten zu vervollkommnen. Wovon hängt es also ab, dass es der Nation an Energie fehlt und dass sie im Allgemeinen als schwerfällig und borniert erscheint, obwohl sie eine kleine Zahl an Männern einschließt, welche vielleicht zu den geistvollsten Europas zählen? [...]

In Deutschland geht das philosophische Genie weiter als überall sonst, nichts hält es auf, und selbst die Abwesenheit einer politischen Karriere, so fürchterlich dies auch für die Masse sein mag, verleiht den Denkern noch größere Freiheit. Aber eine unermessliche Distanz trennt die Geister von erstem und von zweitem Rang, weil es weder das Interesse noch den Gegenstand hinsichtlich Aktivitäten für die Männer gibt, die sich nicht auf die Höhe der weitreichendsten Konzeptionen erheben. Derjenige, der sich in Deutschland nicht mit dem Universum beschäftigt, hat wirklich nichts zu tun. ${ }^{6}$
\end{abstract}

In dieser schönen Passage wird im Grunde das Land der Dichter und Denker, das Land der großen Philosophen auf den Boden der Tatsachen zurückgeholt: Noch stand Deutschland ein großes Jahrhundert der Philosophie bevor; doch die Beschreibung von Madame de Staël wirft ein eigentümliches Licht auf jene Größendimensionen des Denkens, die nicht erst mit Kant, sicherlich auch mit Hegel der deutschen Philosophie wie auf den Leib geschrieben scheinen. Denn es ist in der Tat ebenso aus der Perspektive der französischen wie der englischsprachigen Philosophie durchaus kurios, dass gerade in jenem Land, das nicht über weltweite Kolonien und Handelsbeziehungen verfügte, unentwegt und mit größter Energie an einer Philosophie der Weltgeschichte und philosophischen Konzeptionen des Universalen gearbeitet wurde. Denn dass gerade dies eine Spezialität der deutschen Philosophie war, ist unbestreitbar; und dass gerade ihr - um mit Humboldt zu sprechen - die empirische Basis fehlte, ist ebenso fraglos der Fall. Mit Germaine de Staël werfen wir auf diese Konstellation folglich einen anderen Blick aus einer unerwarteten, aber durchaus fruchtbaren Perspektive

So beschäftige man sich in Deutschland, Madame de Staël zufolge, intensiv mit dem ganzen Universum; doch die Spitze der Wissenschaft sei ungeheuer schmal. Zugleich sei die Verbindung zur Politik, also zur praktischen Umsetzung all dieser Gedankenflüge nicht gegeben: Auch auf dieser Ebene fehle die Verbindung und Vermittlung, fehle das Bindeglied. Sie können bereits erkennen, wie aus der Gegenüberstellung von Frankreich und Deutschland sich hier auch eine mögliche Ergänzung abzeichnet, ja sich eine Komplementarität geradezu aufdrängt.

Die absolute, von der konkreten Welt abgehobene Spekulation, die sich im deutschen Idealismus entfaltete, wird so in einen kulturellen und politischen Zusammenhang gebracht, welcher dem Lesepublikum erklären soll, warum es

6 Staël, Germaine de: De l’Allemagne, Bd. 1, S. $153 \mathrm{f}$. 
gleichsam zu diesen ungeheuren philosophischen Systemen kommen konnte (und auch weiterhin in Deutschland kommen sollte). Dieser Ansatz ist wahrlich aufschlussreich, wenn er hier auch weniger auf einer konkreten Analyse der Umfelder als auf einer Applizierung bestimmter pauschalisierender Bilder beruht. Doch Deutschland erscheint in den Augen der Verfasserin von De l'Allemagne in der Tat als ein Gegenbild Frankreichs, ohne dass dieser Gegensatz von ihr doch allzu sehr in Schwarz-Weiß-Manier ausgemalt wird.

Untersucht man vor dem Hintergrund des weiteren Verlaufs der romantischen Bewegung oder - wie Heinrich Heine sie nennen sollte - der romantischen Schule diese Überlegungen der Germaine de Staël, so fällt auf, wie sehr sie noch in der Tradition der Salons und der Salonkultur des 18. Jahrhunderts stand. Letztere ist es, die ihr in Deutschland fehlt und nicht nur ihr, denn in der Tat war Berlin in dieser Hinsicht eine - wie Alexander von Humboldt es einmal formulierte „Sandwüste“. Dort konnten allein noch die jüdischen Salons, die Salons großer jüdischer Frauen wie Henriette Herz oder Rahel Levin Varnhagen, ${ }^{7}$ sowie die Zirkel der Künstler, Musiker und Gelehrten einige wichtige Akzente setzen.

Doch war es ohne Frage überaus zutreffend, dass die wissenschaftliche Betätigung ungeheuer distant und entfernt von der Vermittlung in andere gesellschaftliche Bereiche war; eine Tatsache, die einer Französin in Deutschland auffallen musste. Wir wissen heute, dass wir noch immer unter diesem Übel leiden, auch wenn sich im wirtschaftlichen und technologischen Bereich manches stark verbessert hat. Denken Sie nur daran, wie lange es dauerte, bis die zahlreichen warnenden Ergebnisse der Klimaforschung langsam, sehr langsam, aber bei weitem noch nicht definitiv in politisches Handeln einflossen - ein Feld, das freilich auch international kaum besser bestellt ist!

Denn selbst jenseits theoretischer Entwürfe und generalisierender Abstraktionen ist es auch heute noch auf dem Feld konkreter und eigentlich handlungsleitender Erkenntnisse ungeheuer schwer, die Ergebnisse der Wissenschaft in die Gesellschaft und in politisches Handeln einzubauen. Deutschland hat noch immer eine gewisse Sonderrolle, was die Kluft zwischen wissenschaftlicher Forschung und konkreter gesellschaftlicher Umsetzung angeht. Dies zeigen im Übrigen nicht nur die Witze, die man sich in anderen europäischen Ländern über deutsche Professoren - insbesondere in Großbritannien - erzählt ... Aber dies ist nicht der Ort für Witze über deutsche Professoren: Von gesellschaftlicher Vermittlungskraft sind sie jedenfalls stets freigesprochen!

7 Vgl. hierzu das Rahel Levin Varnhagen gewidmete Kapitel in Ette, Ottmar: Mobile Preußen. Ansichten jenseits des Nationalen. Stuttgart: J.B. Metzler Verlag 2019. 
Die angesprochene Malaise belegen auch die unterschiedlichsten Veranstaltungen des Alltags, in denen die deutsche Universität kaum zu Wort kommt. Gewiss spielt an dieser Stelle auch der politisch ,kontrollierte' Status deutscher Professor`innen, die als Staatsdiener dem Obrigkeitsstaat verpflichtet waren, eine Rolle. Die Funktion des Intellektuellen ist jedenfalls in Deutschland historisch insbesondere im Vergleich zu Frankreich wenig ausgebildet, und eben dieses Element ist ein Manko, das sich durch die Geschichte der deutschen Intellektuellen zieht: ${ }^{8}$ Denn noch heute gibt es auf diesem Gebiet signifikante Unterschiede.

Gleichzeitig wird deutlich, dass Madame de Staël durch die Betonung des Geselligen, der gemeinschaftlichen Vermittlung und wechselseitigen Erprobung in fast spielerischer, in jedem Falle aber sozialer Art und Weise die Einsamkeit noch nicht als zentrales Element einer romantischen Disposition positiv in Wert gesetzt, ja vielleicht noch nicht einmal erkannt hat. So wird auch an dieser Stelle ihre Verbundenheit mit der literarischen Salonkultur des 18. Jahrhunderts und mit einem Modell der „conversation“ erkennbar, das sie sehr erfolgreich nicht nur in Paris, sondern vor allem dann in Coppet praktizierte: Madame de Staël steht nicht für das einsame Genie der Romantik. Denn es ist bei ihr noch nicht der absolute Geist, der besonders hervorgehoben und mit der Beleuchtung einsamer Größe des Individuums herausgeputzt wird, sondern der fehlende gesellschaftliche Vermittlungszusammenhang, welcher für sie nach wie vor eine entscheidende Größe darstellt. Auf jene andere des einsamen Denkers und Poeten aber wird die Romantik - aber auch das Romantikbild Deutschlands - später alles setzen.

Schon früh war Germaine de Staël gut über Deutschland informiert, nicht zuletzt über den damaligen Herausgeber der Correspondance littéraire, Jacob Heinrich Meister. Bereits verwiesen wurde darauf, dass sie mit dem Autor des Werther korrespondierte, obwohl ihr Interesse an der deutschen Literatur sich erst recht spät entwickelte, und dass Goethe eine frühe Schrift der Französin für Die Horen ins Deutsche übersetzte. Madame de Staël war gewiss nicht von den Vorurteilen der französischen Öffentlichkeit gegenüber den Deutschen und der deutschen Literatur frei; doch zeigte sie - zweifellos durch das Exil verstärkt eine interkulturelle Offenheit, die sie durchaus zu einer wichtigen Vordenkerin

\footnotetext{
8 Vgl. hierzu Jurt, Joseph: Status und Funktion der Intellektuellen in Frankreich im Vergleich zu Deutschland. In: Krauß, Henning (Hg.): Offene Gefüge. Literatursystem und Lebenswirklichkeit. Festschrift für Fritz Nies zum 60. Geburtstag. Tübingen: Narr 1994, S. 329-345; ders.: L'érudit allemand: un mythe français en voie de disparition? In: Melanges offerts à Jacques Grange. Nantes 1989, S. 233-247; sowie ders.: Intellektuelle - Elite - Führungskräfte. Bildungswesen in Frankreich und Deutschland. Freiburg: Frankreich-Zentrum 2004.
} 
Europas machte. Denn in der langen Filiation, die über Victor Hugo und die Autoren des „Entre-deux-Guerres“ zur heutigen Europäischen Union führt, ${ }^{9}$ war Germaine de Staël ganz ohne Zweifel eine wichtige Pionierin. Denn sie versuchte nicht allein, verschiedene europäische Literaturen zu erfassen, sondern auch die Frage nach einer Europa gemeinsamen Kultur zu stellen und - was vielleicht noch mehr ist - auch zu leben.

Die Vorstellung, dass es nicht ein einheitliches Europa, sondern ein Europa der Vielheit und Verschiedenheit geben sollte, in dem sich die unterschiedlichen Regionen und Nationalstaaten wechselseitig ergänzen, ist sicherlich noch immer sehr aktuell und macht vielleicht den Kern der europäischen Differenz gegenüber anderen supranationalen Entwürfen aus. Die beiden wichtigsten Etappen ihrer ersten Deutschlandreise - und sie prägten ihr Deutschlandbild entscheidend mit - waren Weimar, wo sie sich vom 13. Dezember 1803 bis 1. März 1804 aufhielt, sowie Berlin. Nicht umsonst bezeichnete Goethe Madame de Staël, vielleicht mit einem Neologismus seiner Zeit, nach anfänglichem Zögern als eine wahrhaftige „Weltfrau“.

Wichtig in Berlin war vor allem der Kontakt zu Fichte, dem Schweizer Historiker Johannes von Müller, sowie auch der kongenialen Rahel Levin Vernhagen, der wir uns bald zuwenden werden, daneben aber dann vor allem dem von ihr enthusiastisch beschriebenen August Wilhelm Schlegel, der ihr viele Türen nach Deutschland öffnete. Den gerade ,freien' August Wilhelm Schlegel machte die Staël gegen ein Jahressalär von zwölftausend Francs bei freier Kost und Unterbringung in Coppet zum Erzieher ihrer Söhne, eine für beide Seiten fruchtbare Beziehung, welche es freilich vor allem der Staël erlaubte, einen tiefen Einblick in die deutschen Entwicklungen nicht nur während ihrer Deutschlandaufenthalte, sondern auch noch lange danach zu gewinnen.

Bezüglich der Abfassung von De l'Allemagne war Schlegel für die „Weltfrau“ von großem Nutzen, auch wenn man begründete Zweifel an der Äußerung Heinrich Heines hegen darf, Schlegel habe der Herrin von Schloss Coppet die entscheidenden Gedanken geradezu eingeflüstert. Die Arbeitsmethode der Staël war sicherlich niemals das einsame Forschen und Schreiben alleine im Arbeitszimmerchen, und so gingen Gespräche mit den unterschiedlichsten Informanten zweifellos in ihre Gedanken wie in ihre Texte mit ein. Insofern wäre es gemäß ihrer oben diskutierten Ansichten sehr wohl selbstverständlich, dass Madame de Staël ihre Ideen mit Schlegel und ihrem ganzen Kreis von Coppet heftig diskutierte.

9 Vgl. hierzu Kraume, Anne: Das Europa der Literatur. Schriftsteller blicken auf den Kontinent (1815-1945). Berlin - New York: Walter de Gruyter 2010. 
Die Problematik der Individualität war zweifellos gerade in Frankreich ein unmittelbar von der Französischen Revolution mitausgelöstes Phänomen, insoweit sich das Individuum angesichts des Zusammenbruchs jenes traditionellen Gesellschafts- und Wertesystems des Ancien Régime im Verbund mit dem Orientierungsverlust der katholischen Kirche zunehmend auf sich selbst zurückgeworfen sah. Dieser persönliche und persönlichkeitsbildende Individuationsprozess ist im Sinne Germaine de Staëls stets kritisch rückzubinden an eine offene Salongesellschaft, welche die Vermittlung herstellt zwischen diesem Zwang zur Individuation und der Vergesellschaftung des Individuums, seiner Verpflichtung, sich in die neue Gesellschaft zu integrieren.

Das Individuum ist mithin keine Erfindung der Romantik, keine Folge einer wie auch immer individualpsychologisch $\mathrm{zu}$ klärenden Befindlichkeit eines einsamen Menschen, sondern an spezifische Entwicklungselemente der französischen wie europäischen Gesellschaft der Aufklärung zurückgebunden. Wir haben in diesem Zusammenhang erneut eine Konfiguration vor uns, welche die in dieser Vorlesung grundgelegten schleifenden Übergänge zwischen dem 18. und dem 19. Jahrhundert betont. Bei Madame de Staël tritt dem Individuum dabei die Natur als eher harmlose, wenn auch nicht ungefährliche Korrespondenz-Natur entgegen, welche noch in gewisser Weise in die zurückhaltenden Farben einer Malerei des ausgehenden 18. Jahrhunderts gepackt ist.

Und doch ist ihre Definition der Beziehung zwischen Natur und Individuum im Kapitel „De la contemplation de la nature“, in dem sie neben Schubert vor allem auf Novalis eingeht und dessen Naturbegriff entwickelt, ein deutlich von der Erfahrung der Romantik eingefärbter und mitgeprägter Begriff. In diesem Kapitel geht die französische Autorin unter anderem auch auf Alexander von Humboldt ein, der hier nur als „M. de Humboldt“ bezeichnet wird, dem sie wohl zuerst im italienischen Neapel begegnet war und dessen Berichte aus der „Amérique méridionale“, aus dem südlichen Amerika die Autorin offenkundig begeistert gelesen hatte.

Es handelt sich bei ihren Lektüren um die Tableaux de la nature und daraus vor allem um „Über die Steppen und die Wüsten“, da dort Humboldt die Umwandlung der trockenariden Steppen in scheinbare Seen und Meere mit einer Beschreibung des Phänomens der Fata Morgana verband. Diese Stelle ist höchst aufschlussreich, doch kann ich hier nur diese eine kurze Passage zitieren, um schließlich den in der Folge entwickelten Naturbegriff von Madame de Staël mit ihren am Ende des Kapitels getroffenen Äußerungen nachvollziehbar zu machen. Sehen wir uns also diese Überlegungen näher an: 
Nicht allein die Natur wiederholt sich selbst, sondern sie scheint die Werke der Menschen nachahmen und ihnen so ein einzigartiges Zeugnis ihrer Verbindungen und Beziehungen mit ihnen geben zu wollen.

Oft ist man beim Anblick einer schönen Gegend versucht zu glauben, dass sie als einziges Ziel besitzt, in uns hehre und edle Gefühle zu erzeugen. Ich weiß nicht, welche Beziehung zwischen den Himmeln und dem Stolz des Herzens, zwischen den Mondstrahlen, welche auf dem Berge ruhen, und der Ruhe des Gewissens besteht, doch diese Gegenstände sprechen in einer schönen Sprache zu uns, und man kann sich dem Erbeben überlassen, das sie verursachen, denn der Seele geht es dabei gut. [...]

Ah! Welch eine Lehre geht von den Schrecken beständiger Zerstörung für die menschliche Rasse aus! Dient dies dem Menschen nicht zur Ankündigung, dass sein Leben woanders ist? Würde ihn die Natur so sehr erniedrigen, wenn die Gottheit ihn nicht wieder erheben wollte? Die wahren Endgründe der Natur sind ihre Beziehungen mit unserer Seele und unserem unsterblichen Schicksal; die physischen Objekte selbst haben eine Bestimmung, welche sich nicht auf die kurze Existenz des Menschen hienieden begrenzt; sie sind da, um zur Entwicklung unserer Gedanken, zum Werke unseres moralischen Lebens beizutragen. Die Phänomene der Natur sollen nicht nur gemäß der Gesetze der Materie verstanden werden, so gut sie auch immer kombiniert sein mögen, sie besitzen vielmehr einen philosophischen Sinn und ein religiöses Ziel, dessen aufmerksamste Betrachtung niemals seine gesamte weite Ausdehnung erkennen kann. ${ }^{10}$

In dieser dichten Passage wird eine Sicht der Natur entfaltet, die sich zweifellos aus dem engen Kontakt der französischen Autorin mit den großen Vertretern der deutschen Romantik heraus entwickelt hat. Die Ausführungen von Madame de Staël lassen sich in gewisser Weise als das Ergebnis einer interkulturellen Lektüre der deutschen Romantik aus französischsprachiger Sicht deuten. Die Natur wird nicht als Materie betrachtet, als eine Welt, die strengen Naturgesetzen unterworfen ist, als komplexer Gegenstand, der in immer kleinere Objekte aufgelöst und analysiert werden kann. Dieser mechanistischen Auffassung der Natur, wie sie die Aufklärung entwickelte, damit zugleich den Naturgesetzlichkeiten auf die Spur kam und durch experimentelle Anordnungen immer mehr in diese materielle Konstellation von Naturphänomenen eindrang, wird eine andere Auffassung von Natur entgegengestellt, die aufs Engste mit dem Menschen verbunden ist und zweifellos eine Korrespondenz-Natur darstellt. Es handelt sich um einen Naturbegriff, der nicht analytisch vorgeht, sondern synthetisch ausgerichtet ist.

Es ist eine Natur, die in der von Germaine de Staël benutzten Formel des ,je ne sais quoi“ die Rationalität der Naturanschauung mit den irrationalen Rest-

10 Staël, Germaine de: De l’Allemagne, Bd. 3, S. $376 \mathrm{ff}$. 
beständen $\mathrm{zu}$ versöhnen sucht ${ }^{11}$ und die wechselseitigen inneren Beziehungen zwischen Mensch und Natur in den Mittelpunkt stellt. Die mechanistische, materielle Naturanschauung, welche alles der materiellen Analyse unterordnet, wird ebenso wenig übernommen wie das Bild einer allgewaltigen, allmächtigen Natur, die für den Menschen das Unermessliche und Absolute schlechthin bedeutet und ihm fremd und fern gegenüber steht. Madame de Staël versucht im Grunde, zwischen beiden Extremen $\mathrm{zu}$ vermitteln und ebenso eine materialistische wie eine mitfühlende, empathische, spirituelle Dimension der Beziehung zwischen Natur und Mensch zu betonen, welche freilich unverkennbar ins Transzendentale hinüberreicht.

Der Mensch und mehr noch das Individuum ist in eine so konzipierte Natur eingebunden, die keinen Seins-Grund an sich hat, sondern allein für den Menschen und dessen Gefühle da ist. Sie dient ihm als Stoff zur Reflexion und Selbstreflexion, bettet ihn in die Schöpfung ein und weist zugleich doch über deren Grenzen hinaus. In Madame de Staëls Überlegungen sind Vorstellungen des Christentums, wie wir sie schon bei Chateaubriand kennengelernt hatten, unmittelbar präsent und gehen in den Naturbegriff ein. Das ,je ne sais quoi“ deutet hierbei an, dass diese Natur zwar gemessen und experimentell erforscht, aber nicht in ihrer ganzen geistig-spirituellen Komplexität durchdrungen werden kann, dass stets ein Restbestand an Irrationalität bleibt. Die Natur kann nicht in ihre Bestandteile aufgelöst werden, sondern beinhaltet Dimensionen, die nicht analytisch, sondern nur synthetisierend vom Menschen erkannt und in das eigene Leben überführt werden können.

So steht im Zentrum der Naturerfahrung des Individuums die Synthese in und durch den Menschen selbst, der die Gegensätze in seinem eigenen Denken, in seinem eigenen Fühlen aufzuheben vermag. Natur ist für Germaine de Staël letztlich ohne ihre Kontemplation durch den Menschen nicht vorstellbar, ebenso wenig wie die Kontemplation des Menschen ohne die Natur vorstellbar wäre. Die Idee des Kosmos als Vereinigung von Ordnung und Schönheit ist an diesem Punkt nicht fern: Die Schöpfung, alles Geschaffene ist zum einen das, was gemessen und untersucht werden kann, zugleich aber doch eine nicht messbare Schönheit, so wie in der Etymologie des Kosmos-Begriffs Ordnung und Schönheit unauflösbar miteinander verbunden sind. Von jenem der Aufklärung ist dieser Naturbegriff meilenweit entfernt: Natur ist nicht auf ein Messbares und Analysierbares reduzierbar.

11 Vgl. hierzu Köhler, Erich: „Je ne sais quoi“. Ein Kapitel aus der Begriffsgeschichte des Unbegreiflichen. In (ders.): Esprit und arkadische Freiheit. Aufsätze aus der Welt der Romania. Frankfurt am Main: Athenäum Verlag 1966, S. 230 ff. 
Neben der Literatur hat Madame de Staël stets der Philosophie in Deutschland ein ganz besonderes Gewicht beigemessen. Innerhalb der deutschen Philosophie wiederum sieht sie den Schwerpunkt im Bereich der Metaphysik, womit sie vor allem die Entwicklung des deutschen Idealismus anvisierte. Auf diesem Gebiet sind ihre eigentlichen thematischen und imagologischen Schwerpunkte innerhalb ihres Deutschlandbildes zu sehen; denn ohne das Land der Denker wäre Deutschland als Land der Dichter nur ein Torso.

Ihre Ausführungen mögen vielleicht für Philosophen von einer nur recht beschränkten Tragweite sein; für das Bild, das man sich im Ausland von der deutschen Philosophie machte, waren ihre Bemerkungen jedoch von kaum zu überschätzender Bedeutung. Diese hohe Meinung zeigt sich ebenso in ihren Äußerungen zu Beginn ihrer Auseinandersetzung mit der deutschen Philosophie wie in ihren allgemeinen Betrachtungen, welche sie dem Kapitel über Immanuel Kant vorausgehen lässt. Dort heißt es mit aller wünschenswerten Klarheit, dass eine spekulative Philosophie von jeher viele Anhänger in den germanischen Ländern gefunden habe, während sich seit den Römern in den lateinischen Ländern die Anhänger einer experimentalen Philosophie in der Mehrheit befänden. Erneut finden wir uns im Angesicht einer simplen, aber wirkungsvollen Zweiteilung Europas.

Einmal mehr sind es diese Zweiteilungen, welche es Madame de Staël erlauben, einen Prozess wechselseitigen Austauschs in Gang zu setzen, der letztlich die Entwicklung der europäischen Philosophie und zugleich der Philosophie Europas nachvollziehbar macht. ${ }^{12}$ Die Völker des Nordens wurden freilich - so die Staël - nicht von diesen hellen, bisweilen sehr abstrakten Vorstellungen der Römer geprägt; denn sie seien fast ausschließlich durch das Christentum zur Zivilisation geführt worden. Damit wird letztlich eine einschlägige kulturelle Differenz begründet: Denn jenseits aller Fissuren und Risse zwischen einem Europa des Ostens und einem Europa des Südens schwebt bei der Anrufung des deutschfranzösischen Motors noch immer die Vorstellung von einer Zweiteilung Europas zwischen einem Europa lateinischer und einem Europa germanischer Herkunft mit. Es sind diese Differenzen und Gegensätze, welche in manchen Entwürfen noch immer die Dynamik eines geeinten Europa vorantreiben müssen, um wirklich zum Ausgleich aller Gegensätze und damit zum Erfolg führen zu können.

Es ist eigenartig, welch eine Dauer und Dauerhaftigkeit diese der Romantik verpflichteten Vorstellungen über einen langen Zeitraum bis hin zum heutigen Tage entfaltet haben. Lassen Sie mich zum Abschluss unserer Beschäftigung mit Madame de Staël diese entscheidende Passage noch einmal aufrufen:

12 Vgl. Staël, Germaine de: De l’Allemagne. Bd. 3, S. 53 f. 
Die spekulative Philosophie hat stets viele Anhänger unter den germanischen Nationen gefunden, ganz wie die experimentelle Philosophie unter den lateinischen. Die Römer, stets sehr geschickt in allen Angelegenheiten des Lebens, waren keine Metaphysiker [...]. Roms Einfluss wirkte nicht auf die nördlichen Völker. Diese wurden fast vollständig vom Christentum zivilisiert, und ihre alte Religion, welche in sich die Prinzipien des Rittertums enthielt, ähnelte den heidnischen Auffassungen des Südens in nichts. Es gab einen Geist der heroischen und generösen Aufopferung, einen Enthusiasmus für die Frauen, welche aus der Liebe einen edlen Kult machten, und schließlich verhinderte die Härte des Klimas, dass sich der Mensch auf die Freuden der Natur einließ, denn er genoss umso mehr die Lüste der Seele. ${ }^{13}$

Hier finden Sie wie in einem Brennspiegel vereint jene grundsätzlichen Zuschreibungen von Außen- und Innenwelt, von Konkretheit und Spiritualität, von Geschäftssinn und Metaphysik, von Oberflächlichkeit und Tiefe, von Galanterie und Liebe, welche die Romantik und ihr Mittelalterbild, nicht zuletzt aber auch das in Europa gängige Deutschlandbild vor der Wende zum 20. Jahrhundert wesentlich mitprägten. Madame de Staël sah zweifellos die germanischen Länder von außen; doch ihr Fremdbild wirkte nicht allein bei den Völkern von ,lateinischer Rasse': Es wurde in weiten Bereichen des deutschsprachigen Raums zu einem Selbstbild, von dem sich viele Elemente durch die Zeit bis heute gerettet haben.

13 Ebda. 